A. LAMBROS

A. POMBORTSIS

A. SIDERIDIS

D. TAMBOURATZIS

\title{
A generalization of the Erlang's $B$ formula
}

Revue française d'automatique, d'informatique et de recherche opérationnelle. Recherche opérationnelle, tome 23, n 3 (1989), p. 283-288.

<http://www.numdam.org/item?id=RO_1989_23_3_283_0>

(C) AFCET, 1989, tous droits réservés.

L'accès aux archives de la revue « Revue française d'automatique, d'informatique et de recherche opérationnelle. Recherche opérationnelle » implique l'accord avec les conditions générales d'utilisation (http://www.numdam.org/ legal.php). Toute utilisation commerciale ou impression systématique est constitutive d'une infraction pénale. Toute copie ou impression de ce fichier doit contenir la présente mention de copyright.

\section{Numdam}

Article numérisé dans le cadre du programme

Numérisation de documents anciens mathématiques

http://www.numdam.org/ 


\title{
A GENERALIZATION OF THE ERLANG'S B FORMULA (")
}

\author{
by A. Lambros $\left({ }^{1}\right)$, A. Pombortsis $\left({ }^{1}\right)$, A. Sideridis $\left({ }^{2}\right)$ \\ and D. Tambouratzis $\left({ }^{2}\right)$
}

\begin{abstract}
In the present paper a generalization of the Erlang's $B$ formula is proposed, for a loss system in which arriving calls follow a Poisson process. The holding time of each call follows a negative exponential distribution.

The application of the results obtained can be used for the improvement of the grade of service, the efficient use of the existing equipment and the appropriate tariff policy and technical planning of the networks.

To evaluate the parameters included in the proposed generalized Erlang's B formula real telexdata taken from the Salonica local area were used.
\end{abstract}

Keywords : Erlang's formula; telex traffic; telex-data; loss probability; Poisson process.

Résumé. - Dans cet article on propose une généralisation de la formule $B$ de Erlang qui se refère à un système avec pertes. Des appels arrivent à une centrale téléphonique suivant un processus de Poisson. La durée de chaque appel suit une distribution exponentielle.

Les résultats obtenus peuvent être appliqués pour améliorer le niveau du service, pour lutilisation efficace de l'équipement existant et pour la tarification et le plan des réseaux téléphoniques.

Pour l'évaluation des paramètres incluse dans la formule générale B de Erlang on a employé des données de telex de la centrale de Salonique.

Mots clés: Formule de Erlang; Trafic de Telex; Donnés de Telex; Probabilité de perte; Processus de Poisson.

\section{INTRODUCTION}

In this paper an attempt is made towards the evaluation, analysis and optimization of the telephone and telex exchanges. For this purpose, real data were used taken from the nodal exchanges of the ESS-SPC technique greek national telex network described in [1].

The time epochs the calls started and the holding time of each call were recorded. They showed that the moments of arrival formed a Poisson process.

(*) Received December 1986.

(1) Physics Department University of Thessaloniki, Greece.

$\left({ }^{2}\right)$ Agricultural College of Athens, Department of Mathematics, Greece.

Recherche opérationnelle/Operations Research, 0399-0559/89/03 283 6/\$2.60

(c) AFCET-Gauthier-Villars 
Attempts to prove that the holding times followed a negative exponential distribution were unsuccessful. Further analysis of the data showed that two different kinds of subscribers could be considered. Subscribers coming mostly from the public sector with excessively long duration of holding times, and subscribers with short duration of holding times of the private sector.

Both the above two categories of subscribers followed satisfactorily an exponential distribution with mean $1 / \mu_{1}$ and $1 / \mu_{2}$ correspondingly, where $\mu_{1}<\mu_{2}$. The stationary state probabilities were evaluated by a new stochastic model and proved to follow a generalized form of the Erlang B formula.

\section{STOCHASTIC MODEL}

The queueing system considered here is defined as follows:

(i) Telex calls $c_{i}, i=1(1) n$, arrive at a telex exchange at the instants $t_{i}$, $i=1(1) n$, in accord with a Poisson process of density $\lambda$. The interarrival times $U_{i}=t_{i}-t_{i-1}, i=1(1) n$ are independent, non-negative random variables with common distribution function,

$$
F(x)=P(U \leqq x)=1-e^{-\lambda x}, \quad x \geqq 0 .
$$

(ii) The holding times of the calls $V_{i}, i=1(1) n$ are independent nonnegative random variables. Then, if the index $j$ denotes the category of the call $\left(j=1\right.$ for calls of long and $j=2$ of short duration) the distribution $H_{j}(x)$ of $V_{i}$ and the average holding time $E_{j}$ are given by

and

$$
H_{j}(x)=P\left(V_{i} \leqq x\right)=1-e^{\mu_{j} x}, \quad x \geqq 0
$$

$$
E_{j}\left(V_{i}\right)=1 / \mu_{j}, \quad \mu_{1}<\mu_{2}
$$

(iii) An arriving call with probability $a$ is of long duration and $1-a$ of short duration.

(iv) The holding times are independently distributed of the interarrival times.

(v) There are $N$ available lines and every call occupies one line. If a call arrives to find all the lines busy, it leaves never to return and we say that it is a "loss" to the system.

Under the above assumptions we can evaluate the stationary state probabilities $P\left(k_{1}, k_{2}, t\right)$, that an arriving call at time $t$ finds $k_{j}, j=1,2$ calls of each kind respectively in process. Here $k_{1}+k_{2} \leqq N$, and $P\left(k_{1}, k_{2}, t\right)$ provides the loss probabilities when equality holds. 


\section{STATE PROBABILITIES}

In this section the state probabilities $P\left(k_{1}, k_{2}, t\right)$ are evaluated. For this the transition probabilities $P\left(k_{1}, k_{2}, t+d t \mid m_{1}, m_{2}, t\right)$ are defined. These are the probabilities that at time $t+d t$ there are $k_{1}$ and $k_{2}$ calls of each kind respectively, given that at time $t$ there were $m_{1}$ and $m_{2}$ calls in process. Then, the only non-zero transition probabilities are:

$$
\begin{gathered}
P\left(k_{1}+1, k_{2}, t+d t \mid k_{1}, k_{2}, t\right)=a \lambda d t+O(d t) \\
P\left(k_{1}, k_{2}+1, t+d t \mid k_{1}, k_{2}, t\right)=(1-a) \lambda d t+O(d t) \\
P\left(k_{1}-1, k_{2}, t+d t \mid k_{1}, k_{2}, t\right)=k_{1} \mu_{1} d t+O(d t) \\
P\left(k_{1}, k_{2}-1, t+d t \mid k_{1}, k_{2}, t\right)=k_{2} \mu_{2} d t+O(d t) \\
P\left(k_{1}, k_{2}, t+d t \mid k_{1}, k_{2}, t\right)=1-\left(\lambda+k_{1} \mu_{1}+k_{2} \mu_{2}\right) d t+O(d t) .
\end{gathered}
$$

After some manipulation of the state probabilities at time $t+d t$ with those at time $t$ and the use of the transition probabilities it is derived the set of differential equations:

$$
\begin{aligned}
P^{\prime}\left(k_{1}, k_{2}, t\right)= & a \lambda P\left(k_{1}-1, k_{2}, t\right)+(1-a) \lambda P\left(k_{1}, k_{2}-1, t\right) \\
& -\left(\lambda+k_{1} \mu_{1}+k_{2} \mu_{2}\right) P\left(k_{1}, k_{2}, t\right) \\
& +\left(k_{1}+1\right) \mu_{1} P\left(k_{1}+1, k_{2}, t\right) \\
& +\left(k_{2}+1\right) \mu_{2} P\left(k_{1}, k_{2}+1, t\right) .
\end{aligned}
$$

The solution of the equations (1) when the system works under statistical equilibrium conditions (independently of $t$ ), is given by

$$
P\left(k_{1}, k_{2}\right)=\frac{\left(a \lambda / \mu_{1}\right)^{k_{1}} 1 / k_{1} !\left[(1-a) \lambda / \mu_{2}\right]^{k_{2}} 1 / k_{2} !}{\sum_{v=0}^{N} 1 / v !\left[\left(a \lambda / \mu_{1}\right)+\left((1-a) \lambda / \mu_{2}\right)\right]^{v}} .
$$

Hence, the probability $\Pi_{c}$ that $c$ lines are busy with calls of either kind is given by,

$$
\Pi_{c}=\sum_{k_{1}+k_{2}=c} P\left(k_{1}, k_{2}\right)=\frac{\left[a \lambda / \mu_{1}+(1-a) \lambda / \mu_{2}\right]^{c} 1 / c !}{\sum_{v=0}^{N}\left[\left(a \lambda / \mu_{1}\right)+\left((1-a) \lambda / \mu_{2}\right)\right]^{v} 1 / v !}
$$

where $0 \leqq c \leqq N$. 
Equation (3) is of the form of the well known Erlang's Loss formula [2]. It is noted that, when a number $c$ of calls of both kinds is in process, the most probable number of calls $k_{0}$ of the first kind is calculated from

$$
P\left(k_{0}, c-k_{0}\right)=\max _{0 \leqq k \leqq c} P(k, c-k)
$$

which provides one or two consecutive integer values for $k_{0}$, namely

$$
\frac{a c \mu_{2}-(1-a) \mu_{1}}{a \mu_{2}+(1-a) \mu_{1}} \leqq k_{0} \leqq \frac{a \mu_{2}(c+1)}{a \mu_{2}+(1-a) \mu_{1}} \text {. }
$$

The above results can be further generalized if the arriving calls are of $n$ different types instead of two. If this is the case i.e.,

- there are $n$ types of exponentially distributed holding times

$$
H_{j}(x)=1-e^{-\mu_{j}(x)}, \quad x \geqq 0, \quad j=1(1) n
$$

and

- a proportion $a_{i}(i=1,2, \ldots, n)$ of calls of $i$-th type arrive at any period of time, where $\sum_{i=1}^{n} a_{i}=1$.

then, the steady state probability that at any time epoch $t$ there are $k_{1}, k_{2}, \ldots, k_{n}$ calls in process, where $\sum_{i=1}^{n} k_{i} \leqq N$, is given by

$$
P\left(k_{1}, k_{2}, \ldots, k_{n}\right)=\frac{\prod_{i=1}^{n}\left(a_{i} \lambda / \mu_{i}\right)^{k_{i}} 1 / k_{i} !}{\sum_{v=0}^{N}\left[\sum_{i=1}^{n} a_{i} \lambda / \mu_{i}\right]^{v} 1 / v !}
$$

and the probability $\Pi_{c}$ that $c$ lines are busy with calls of any kind, is given by,

$$
\Pi_{c}=\frac{\left[\sum_{i=1}^{n} a_{i} \lambda / \mu_{i}\right]^{c} 1 / c !}{\sum_{v=0}^{N}\left[\sum_{i=1}^{n} a_{i} \lambda / \mu_{i}\right]^{v} 1 / v !}, \quad 0 \leqq c \leqq N .
$$




\section{NUMERICAL RESULTS}

In this section the behaviour of $P\left(k_{1}, k_{2}\right)$ is examined when

- calls arrive in accord with a Poisson process of density $\lambda$,

- the holding times of the calls are exponentially distributed,

- a proportion " $a$ " of the calls have average holding time $1 / \mu_{1}$ and the remaining $1 / \mu_{2}, \mu_{1}<\mu_{2}$ and $R=\mu_{2} / \mu_{1}$ and,

- there is a number $N$ of available lines, for different values of the parameters, $\lambda / \mu_{1}, R, N$ and $a$.

As an example it is considered the case where

$$
N=5, \quad R=5, \quad \frac{\lambda}{\mu_{1}}=888.5, \quad k_{1}+k_{2}=5,
$$

and $a=0.01(0.01) 0.99$ (see Fig.).

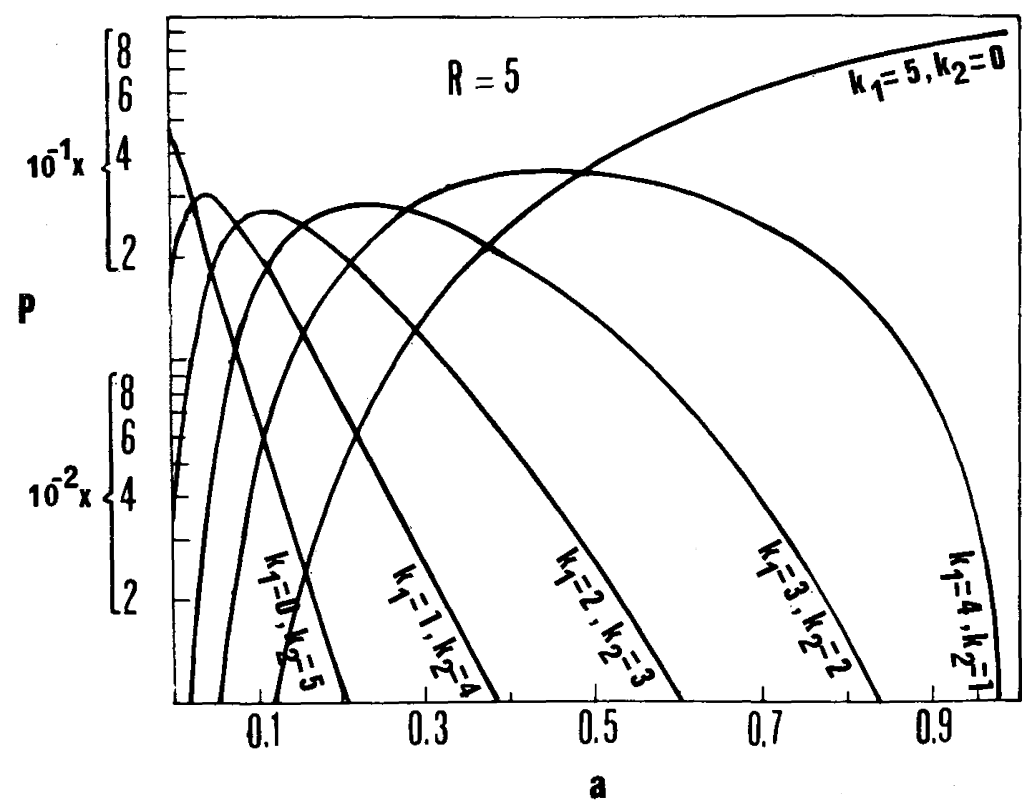

Figure. - Variation of $P\left(k_{1}, k_{2}\right)$ for different values of $0<a<1$.

The importance of the formulae (3) and (7), as expressions of the behaviour of the Erlang's Loss Probability function lies on the fact that the variety of subscribers, with different holding times, necessitates the use of such more general formulae. This variety is well represented by the real data taken 
during the busy hour of a working day in the local area of Salonica. Salonica was selected since it represents an industrialy developed area of Greece. It has 2000 telex subscribers covering the whole spectrum of the economic activities and is considered to be the centre of social and financial life of northern Greece.

It is found that during the busy hour the average interarrival time between two consecutive telex calls was $1.3 \mathrm{sec}$. The results show that there are also great discrepencies among the average holding times of different types of subscribers such as those of the following Table.

TABLE

Distribution of telex calls in Salonica local area and the corresponding average holding times

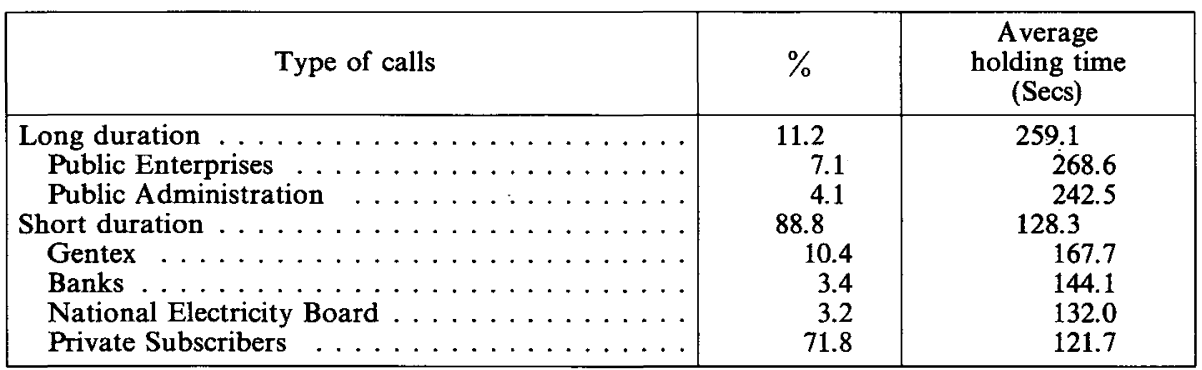

The data of the Table can be used for an evaluation of the parameters of formulae (2) to (7).

\section{CONCLUSIONS}

From the analysis of section 3 follows that the loss probability, i.e. the probability that an arriving call finds all the lines busy and leaves the system never to return, is given by equation (2). For $c=N$ this equation is of the form of the Erlang B formula and, as such, allows the use of all the previous analyses, tables, curves, iterative relations etc.

Formula (3) can be used for the evaluation of the number $N_{0}$ of channels for which $\Pi_{N_{0}}<p_{0}$, where $p_{0}$ is a given probability representing the proportion of lost traffic. Finaly, if to the above results will be added that formulae (2) to (7) hold good when the holding times follow practicaly the two different distributions shown in Table, then it can safely stated that these formulae provide a good guide to the PTT services for an appropriate invoice policy.

\section{REFERENCES}

1. A. P. Lambros, L. Gabrielidis and H. Polatoglou, Erlang and Normal Distributions in Telex Traffic, I.E.E.E. Transactions on Communications, 29, $\mathrm{n}^{\circ} 7,1036,1981$.

2. L. KleINRock, Queueing Systems Theory, I, J. Wiley, 1975. 